\title{
The Influence of Surface Modification Using Low-Pressure Plasma Treatment on PE-LLD/ $\alpha$ - Cellulose Composite Properties
}

\author{
Martin Boruvka ${ }^{1}$, Chakaphan Ngaowthong ${ }^{2,3}$, Jiri Cerman $^{1}$, Petr Lenfeld ${ }^{1}$, Pavel Brdlik ${ }^{1}$ \\ ${ }^{1}$ Faculty of Mechanical Engineering, Technical University of Liberec, Studentská 2, 46117 Liberec 1, Czech Republic. \\ E-mail: martin.boruvka@tul.cz,j.cerman@post.cz, petr.lenfeld@tul.cz,pavel.brdlik@tul.cz \\ ${ }^{2}$ The Sirindhorn International Thai - German Graduate School of Engineering (TGGS), King Mongkut's University of \\ Technology North Bangkok, 1518 Pracharat 1 Road, Bangsue, Bangkok 10800, Thailand. \\ ${ }^{3}$ Faculty of Industrial Technology and Management, King Mongkut's University of Technology North Bangkok Pra- \\ chinburi Campus, 29 Moo 6, Tumbon Noenhom, Amphur Muang, Prachinburi 25230, Thailand \\ E-mail: chakaphan.n@fitm.kmutnb.ac.th
}

The use of plant source-based stiff fillers as reinforcement of polymer composite systems have attracted significant interests of researchers during last few decades. Unlike synthetic fibres, plant fibres are renewable, carbon neutral, biodegradable, non-petroleum based, and have low environmental, human health and safety risks. Moreover plant fibres have potential to reduce weight of composite parts up to $40 \%$ compared to the traditional synthetic composite reinforcement like glass fibres. The main disadvantage of plant fibres lies in combination of non-polar polymer matrix (hydrophobic) and polar plant fibres (hydrophilic). This combination creates poor interface with low adhesion of both components. That implies poor wettability of fibres by polymer matrix and low mechanical properties of composites. To improve the compatibility various methods have been explored to increase the hydrophobicity of plant fibres. The most used method is chemical surface treatments of fibres with large quantities of hazardous chemicals that are usually involved in the process. Therefore more greener sustainable technology, that is environmentally friendlier and industrially scalable was investigated in this paper. The process based on lowpressure plasma treatment of both fibres ( $\alpha$-cellulose) and matrix (PE-LLD) was implemented in processing of composites by twin screw extrusion and injection moulding. Resulted composites were characterized by means of scanning electron microscopy (SEM), thermal and mechanical testing.

Keywords: Polymer composite, Plasma treatment, Lightweight, Surface modification, Cellulose

\section{Acknowledgement}

This paper was written at the Technical University of Liberec with the support of the Specific University Research Grant SGS, as provided by the Ministry of Education, Youth and Sports of the Czech Republic in the year 2016.

\section{References}

[1] MARCH G. (2003) Next step for automotive materials. Materials Today. 6, issue 4.

[2] KAliA, S., DUFRESNE, A., CHERIAN, B. M., KAITH, B. S., AVÉROUS, L., NJUGUNA, J., NASSIOPOULOS, E., (2011) Cellulose-Based Bio- and Nanocomposites: A Review. International Journal of Polymer Science, vol. 2011.

[3] [3]MOHANTY, A. K., MISRA, M., DRZAL, L. T., (2005). Natural fibers, biopolymers, and biocomposites. Taylor \& Francis, Boca Raton.

[4] MÜSSIG J. (2010). Industrial application of natural fibres: structure, properties, and technical applications. Wiley, Chichester, West Sussex, U.K.

[5] KALIA, S., KAITH, B. S. and KAUR, I. (2011). Cellulose fibers: bio- and nano-polymer composites. Springer, Berlin.

[6] DUFRESNE A. (2012). Nanocellulose: From Nature to High Performance Tailored Materials. Walter de Gruyter $\mathrm{GmbH} \& \mathrm{Co} . \mathrm{KG}$.

[7] DUFRESNE A. (2013). Nanocellulose: a new ageless bionanomaterial. Mater. Today, vol. 16, no. 6

[8] ZIMMERMANN, T., POHLERAND, E. and GEIGER, T. (2004). Cellulose fibrils for polymer reinforcement. Advanced Engineering Materials 6, No. 9.

[9] REITER, G., STROBL, G. R. (2007). Progress in understanding of polymer crystallization, Springer, vol. 714 